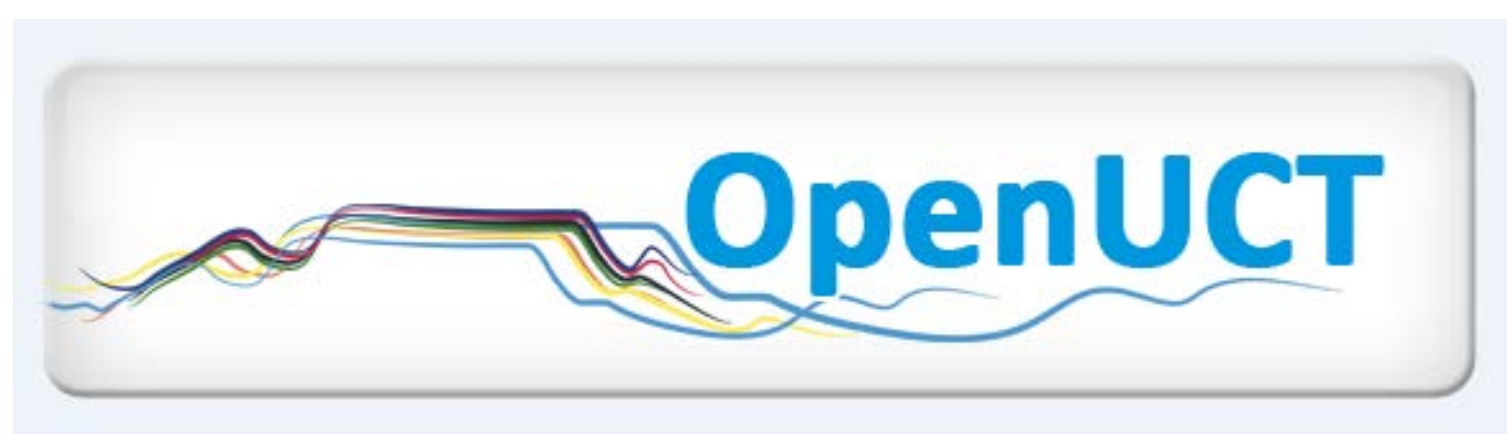

This is the post-print Shay, S. 2008. Assessment at the boundaries: service learning as case study. British Educational Research Journal. 34(4): 525-540. DOI: 10.1080/01411920701609406.

It is made available according to the terms of agreement between the author and the journal, and in accordance with UCT's open access policy available: http://www.openuct.uct.ac.za/sites/default/files/UCTOpenAccessPolicy.pdf, for the purposes of research, teaching and private study. 


\title{
Assessment at the boundaries: Service learning as case study
}

\author{
Suellen Shay* \\ Centre for Higher Education Development \\ University of Cape Town
}

\begin{abstract}
This paper explores the value systems which inform assessment practices in higher education, specifically how particular forms of knowledge valued in the curriculum shape and constrain assessment practices. The data for this paper is drawn from two courses which participated in a service learning research and development project at UCT. Drawing on Pierre Bourdieu and Basil Bernstein, the paper argues that the location of these courses -- within the field of higher education and a particular kind of institution, faculty and department -- shapes their assessment systems, practices and outcomes in certain ways. What is valued in this field (Bourdieu) is a form of knowledge production which requires students 'to step out of the particularities'. This form of knowledge operates as a regulative discourse, constituting what counts as legitimate. Using the assessment system as a 'window' this paper explores how these service learning courses constitute and are constituted by the regulative discourse of the field. While the constraints of the field are powerful, this project offers some hopeful signs of forms of curriculum, pedagogy and assessment that, at the very least, name and challenge these underlying value systems.
\end{abstract}

\section{Introduction}

There is a substantial body of literature which applies a critical social gaze to curriculum by exploring the principles or values which underlie curriculum and the implications for what constitutes valid forms of knowledge. This literature addresses questions such as: What constitutes 'curriculum for the future'? (Young 1998); What concepts of knowledge underpin these curriculum? (Young 2003); What kinds of knowledge are appropriate for the millennium citizen? (Muller 2000). With a specific focus on higher E-mail: sshay@ched.uct.ac.za 
education curriculum Barnett \& Coate (2005) ask, what kinds of knowledge are going to be fruitful in a changing world? Given South Africa's transformation agenda, particular questions are being debated around ‘curriculum responsiveness’ (Moll 2004) and the management capacity of higher education institutions to be 'responsive' (Moore and Lewis 2004). Implied in these debates, and in some cases explicitly argued, is a contemporary erosion of the boundaries which have traditionally demarcated subject knowledge, as well as the boundaries between higher education and other key sectors of society, for example, industry, government and the economy in general. There seems to be broad agreement that one of the implications of this weakening of boundaries is an increasing demand on higher education to produce graduates capable of complex performances, although the precise nature of these complex achievements remains the subject of wide-ranging debate (Muller 2000, Barnett \& Coate 2005, Knight \& Yorke 2003).

While this literature has succeeded in exposing the contested terrain in which curriculum choices are made, the implications for assessment of these complex performances are either assumed or neglected. If the weakening of boundaries necessitates increasingly complex performances, there has been insufficient debate about the resulting consequences for assessment in higher education. Much of the current higher education assessment literature, and the teaching and learning literature more generally, is dominated by a skills or outcomes discourse (Barnett \& Coate 2005). In service of the accountability regime, much of the assessment literature is characterized by advocacy for explicit learning outcomes, appropriate assessment methods and transparent grading criteria all the while ignoring the messy social practice entailed in these 'good practice' principles. The result in pedagogical practice is the proliferation of course and programme learning outcomes, as well as graduate profiles which are aspirational at best and vacuous at worse. The production of these graduate wish-lists seldom emerge from a careful consideration of whether, firstly, such attributes logically flow from the value bases of the curriculum, and secondly, whether these attributes are assessable in any meaningful way.

E-mail: sshay@ched.uct.ac.za 
Can these complex performances be assessed? The principle of constructive alignment (Biggs 1996) advocates a correspondence between what academics value, what they teach and what is assessed. But are these complex performances which higher education claims to value assessable? For example, can autonomy, interpersonal relations and leadership - all things which employers say they value (Knight and Yorke, 2003) - be assessed? In the context of an accountability regime and its increasing pressure on higher education to warrant student achievements for high-stakes purposes, Knight (2005) argues that complex achievements will "resist reliable, fine-grained, valid and affordable judgments” (p. 99). From an epistemological perspective, complex performances involve kinds of knowledge which are not measurable in any accurate and precise way. They often require judgments which are contextually embedded and therefore cannot achieve the levels of generalizability required of the measurement paradigm (Knight in press, Shay 2005). Thus Knight is not arguing that complex performances cannot be assessed, but that they cannot be affordably assessed with sufficient levels of reliability for warranting high stakes achievements.

As a way forward through this assessment conundrum, Knight (in press) proposes that we need a differentiated assessment approach, that is, to think about assessing differently and for different purposes. Differentiated assessment does not simply mean a diversity of assessment methods. A differentiated approach recognizes that complex performances are constituted by different kinds of knowledge, requiring different kinds of judgment. I propose that our ability as a higher education community to assess complex performances in increasingly meaningful ways requires a more sophisticated understanding of the forms of knowledge inherent in these performances. Empirically, this will require detailed analyses of curricula at the intersection of their constitutive fields and sub-fields (e.g. academe, the discipline, and the profession), as well as analyses of the academic habitus, that is, the ways in which academics' internalization of the values of these fields constitute their interpretive frameworks. Against the backdrop of this longer-term project, the aim of the study reported on in this paper is modest and serves principally to open up debate. Drawing on the work of sociologists of education Pierre Bourdieu and Basil Bernstein I bring a particular set of theoretical tools to interrogate the assessment E-mail: sshay@ched.uct.ac.za 
products of two service learning courses with a particular interest in the kinds of knowledge which are being privileged in these assessment events.

\section{Service learning curriculum as boundary-work}

Numerous national policy initiatives during the 1990's have attempted to steer the restructuring of curriculum in South African higher education (National Commission on Higher Education (NCHE) 1996, Government Gazette Education White Paper 3 1997, South African University Vice Chancellor (SAUVCA) 1999). Moore (2000) identifies two governing discourses in these policies: the global trend in higher education towards the production of flexibly skilled graduates and the local context of post-apartheid development imperatives. He argues that the logic of these policies connects the social purposes of South Africa as a 'developing country' with a need for programmes that are 'educationally transformative' and that the characteristics of such programmes include the fact that they are "planned, coherent and integrated” (SAUVCA 1999 in Moore 2000). The interpretation of 'planned, coherent and integrated' programmes at the institutional policy level has varied considerably. The University of Cape Town's attempts to realize these national aspirations for curriculum reform through policy have been singularly unsuccessful. There are to date, for example, no operative institutionwide sets of guidelines or principles informing graduate competencies at UCT. This has not been altogether a bad thing. Where programmes have been 'responsive', the drivers for reform have tended to be intrinsic to the discipline or field of practice rather than compliant with external requirements.

It is in this context that the Centre for Higher Education Development (CHED) established a service learning research and development project which ran during the period of 2004-2005. The service learning movement in South Africa has emerged as one response to the White Paper's (Government Gazette 1997) call for a more responsive higher education sector, by providing students with opportunities for community engagement which is formally integrated into the university’s core business of teaching E-mail: sshay@ched.uct.ac.za 
and research. McMillan (2002) argues that service learning involves boundary work and one of the aims of this project is to theorize this boundary work.

The project drew together UCT academics who were grappling with the challenges of running courses that, in one way or the other, involved students in 'service' or what some of the project participants preferred to refer to as community-based learning. In each of these courses, as a formal part of the assessment requirements, students had to produce assignments which required them to engage with communities outside the university, for example, a funding proposal for a non-government organization, a risk disaster assessment in an informal settlement, a survey of backyard living conditions in a township, and a health promotion report for a primary health care clinic. One of the recurring themes among the project participants was the challenge of assessing student learning in these courses. In contrast to other courses where the 'what and how' of assessment is often a taken-for-granted, unproblematic occurrence, these colleagues continually challenged their own and each others’ practices. Their critiques extended beyond issues of assessment method - should we assess students in groups or individually? -- to considerations of what kinds of knowledge are legitimated in their existing assessment practices, and by what criteria are students’ performances judged.

These questions were inevitable. While these service learning courses differ in many ways - some located in professional degrees, some in formative degrees -- they all share a commitment to pushing the boundaries that traditionally define higher education curriculum - boundaries between institutions, agents and practices (Bernstein 2000). My interest was therefore how these shifting boundaries pose challenges for assessment, and the central research question is, what is being assessed and what is not being assessed and why?

\section{Assessment as social practice}

E-mail: sshay@ched.uct.ac.za 
Underlying this research question is a theoretical interest in assessment as a social practice. To refer to assessment as a social practice is to acknowledge the multiple contexts which constitute assessment judgments. These multiple contexts include the macro-social conditions of the field (Bourdieu) and the ways in which these conditions legitimate particular classificatory systems, the meso-level disciplinary and subdisciplinary communities of practice with their specific epistemological orientations, and finally the micro-level contexts of assessors' interpretive frameworks. As I have argued elsewhere (X 2004), academic assessment practices only make sense within the logic of the field of academe and its disciplinary sub-fields. For it is this field and its sub-fields that determine the epistemic “principles of vision and division” (Bourdieu 1996, p.1) which inform assessment-based interpretations: what is perceived to be legitimate knowledge, the legitimate criteria for assessing this knowledge, and the legitimate assessors of this knowledge.

Thus assessment is a value-based judgment. These judgments are doubly constituted by the objective and the subjective modes of knowledge where, drawing on Bourdieu (Bourdieu and Wacquant 1992) the 'objective' refers to how judgments are constrained by the regularities of the field which are internalized through membership in the field, and the 'subjective' refers to how judgments are influenced and constrained by assessors' position (X 2005). In previous research my empirical work focused on the latter, in particular how the assessor's relation to and investment in the learner and their performance influences assessment judgments. This inquiry shifts attention to the more objective constitution - the forms of 'capital' valued by the discipline, the institution and the field which shape and constrain assessment. The particular interest is in knowledge -the ways in which the disciplines and their sub-fields determine the legitimate forms of knowledge. But fields are always sites of struggle and contestation over what is to be valued, and assessment systems and practices offer an interesting window into these contesting value systems. As Moore argues, “Assessment practices will always be a critical barometer of the 'contradictions, cleavages, and dilemmas' inherent in the complex and changing social processes of pedagogy” (2000, p. 197).

E-mail: sshay@ched.uct.ac.za 
While Bourdieu's concepts of field and capital are useful "thinking tools" for illuminating the competing stakes in assessment, they are somewhat blunt analytical instruments for illuminating the what and why of the contestation. As Muller (2000) argues there is a need for a more textured language of description for the forms and flows of knowledge as capital within and between fields. For this I draw on Basil Bernstein.

Berstein, like Bourdieu, is interested in underlying principles or values which inform the classification of what counts as valid knowledge. Bernstein (1975) argues that educational knowledge is realized through three message systems: the curriculum which defines what counts as valid knowledge, pedagogy which defines the valid transmission of knowledge, and evaluation which defines the valid realization of the knowledge by learners. While Bernstein has been used extensively in South Africa to theorize curriculum and pedagogy (Breier 2004, Ensor 2002, Moore 2000 and 2004, Muller 2000), my particular interest is in the relationship between curriculum and evaluation the relationship between what counts as valid knowledge and what constitutes legitimate performance. There has been some application of Bernstein's theory to explore assessment in schools in the U.K. (Broadfoot \& Pollard, 2000) but little application of his work to assessment in higher education (exceptions include Moore 2000).

Central to Bernstein's (1975) explanatory framework are the concepts of classification and framing. Classification refers to the strength of the boundaries between subject content and thus relates to issues of curriculum. Framing refers to the relationship between teacher and learners and thus relates to issues of pedagogy ${ }^{1}$. According to Bernstein's model, the strength of classification produces two different types of curriculum: collection type and integrated type. The former refers to curricula where the boundaries between content subjects are strong, in other words, subjects are clearlybounded and isolated from each other. In contrast, in integrated type curricula subject boundaries are weak or blurred, in other words, subjects are more open to each other.

\footnotetext{
${ }^{1}$ This focus of this paper is on relationship between curriculum and evaluation. Issues of pedagogy as they are manifested through framing are crucial to assessment but outside the scope of this paper.

E-mail: sshay@ched.uct.ac.za
} 
This weakening or blurring of boundaries between subjects is a result of the subordination of content to, what Bernstein refers to as, an 'integrating idea' -- a logic external to the discipline, for example, a common problem or theme arising from the field of practice (Moore 2004).

There are a number of implications in what Bernstein observes as a contemporary move from collection type to integrated type curriculum. Relevant to this analysis is how the weakening of classification between subjects impacts on what counts as valid knowledge and thus what gets assessed. Specifically Bernstein notes that, relative to the collection type, integrated curriculum may weaken the boundaries between uncommon sense (or educational) knowledge and common sense (or everyday) knowledge (1975, p. 99, 106). In subsequent work (1999, 2000) Bernstein elaborates on these different forms of knowledge as discourses - vertical and horizontal. Horizontal discourse refers to everyday knowledge, knowledge which is context-dependent, procedural, and segmented. Meaning is derived from the particular - the context, the problem, the experience. In contrast, vertical discourse is theoretical knowledge, knowledge which is abstract and generalizable. The disciplinary forms of knowledge which circulate in the university (as capital) are examples of vertical discourse, knowledge which is "freed from the particular, the local, through the various languages of the sciences or forms of reflexiveness of the arts which makes possible either the creation or the discovery of new realities” (1975, p. 99).

Bernstein's concept of classification and the implications for curriculum are helpful for understanding some of the challenges for service learning as boundary-work. Particularly relevant is Bernstein's argument that changes in the nature and strength of boundaries involve changes in what counts as having knowledge, the valid transmission of knowledge (pedagogy), the valid realization of knowledge (evaluation) as well as changes in social relations (1975, p. 104). What is less helpful is Bernstein's distinction between vertical and horizontal discourses for the purposes of understanding the more complex performances which may be required as a result of weakened boundaries. The concept of vertical discourse (or theoretical knowledge) and the different kinds of E-mail: sshay@ched.uct.ac.za 
'verticality' which distinguish the sciences provide a useful language of description for a very particular kind of capital valued in the academic field. But not all university pedagogy is made up of 'vertical' forms of knowledge (see Breier's 2004 study of Law). There are strong resonances particularly in professionally oriented curricula of some of the features of horizontal discourse, for example, knowledge which can only be activated in context, which is strongly affective and can only be tacitly acquired through modeling and practice. Bernstein's vertical/horizontal discourses appear to be limited as a language for describing the terrain of complex performances required of service learning. Bernstein does acknowledge that the weakening of boundaries may necessitate the recruitment of different forms of knowledge - what he refers to as “inner attributes” (1975, p. 109) or dispositions which are consistent with the integrating ideology. More useful may be the curriculum frame developed by Barnett and Coates (2005) which involves a triad of knowing, acting and being, arguing that in addition to theoretical knowledge there are other knowledges, for example, dispositional knowledge, which are crucial components of some contemporary curricula.

As noted above integrated type curricula cohere to a logic which is external to the individual subjects which make up the curriculum, for example, an orientation to the field of practice. This orientation to an external logic may necessitate the recruitment of different forms of knowledge than what are typically privileged in the collection. This presents a set of challenges which have implications for assessment (Berstein 1975). Firstly, in contrast to collection type curricula where the insularity of subjects can accommodate a range of ideologies, integrated type curricula require high levels of ideological consensus among staff. In other words, the staff has to 'buy into' the 'integrating idea'. Secondly, a co-ordinating framework is required which links the integrating idea to choices about what knowledge is selected. The development of a coordinating framework is essential for the socialization of staff into the requisite interpretive procedures. Thirdly, in collection type curriculum with its tightly bounded subjects - into which the staff has been socialized through their specialist training -- the criteria for evaluating what constitutes valid knowledge are more or less established. This does not mean that the criteria are explicit; they are simply established as a result of a E-mail: sshay@ched.uct.ac.za 
long process of internalization - as I argue elsewhere the criteria form part of the academic habitus (X 2004). In Bernstein’s words: “The established criteria together with the specific social context of assessment create a relatively objective procedure” (Berstein, 1975 p. 109). In contrast, in integrated type curricula, Bernstein argues the criteria are likely to be weakly defined. The establishment of criteria requires on-going negotiation between staff and among students and staff.

To re-cap, Bernstein's concepts expose some of the complexity of service learning as boundary work, in particular the assessment challenges. The weakening of boundaries between subject, discipline and institutional knowledge domains may result in new forms of knowledge in addition to the traditional theoretical knowledge which universities privilege. In shorthand I refer to these as 'being' and 'doing' knowledge (Barnett and Coate 2005). Academic staff may to varying degrees be successful in creating rich pedagogical opportunities where students can practice and display these different kinds of knowledge. However the difficulty of formally valuing these knowledges is often underestimated. A particular challenge which Bernstein alerts us to is the absence of established interpretive frameworks. Assessment criteria fail to be operative in any meaningful way since the interpretive frameworks which these curricula require are not in place. These criteria can only become normative through the socialization processes by which any classificatory system becomes internalized.

Drawing on Bernstein's explanatory model, I now turn to explore the assessment of field research projects in two service learning courses; the central question being, what is being assessed and what is not being assessed and why?

\section{Service learning courses as cases}

The service learning project attracted staff at UCT from six different courses - two in the Faculty of Humanities, two in Science and two in Health Sciences. For the purposes of this exploration I selected the two Science courses, Urban Geography 300 and Risk Disaster Science 400 (henceforth referred to as UG300 and RDS400) both located in the E-mail: sshay@ched.uct.ac.za 
Environmental and Geographical Sciences department. While located in the same department, the position of these courses within their respective programmes is different. UG300 is an undergraduate course which serves as a final year elective for students specializing in Human Geography. RDS400 is a postgraduate course which serves as the introductory core course of the Risk Disaster Science programme. These courses were selected because initial conversations with staff suggested that they might be positioned at different points on Bernstein's collection/integrated curriculum continuum; I was interested in how these different positions might influence the assessment. The analysis focuses on the assessment of the field research projects and data is drawn principally from interviews with staff involved in these projects.

\section{UG300 field research project}

Consistent with the undergraduate-postgraduate trajectory of many university programmes, the process of becoming a human or urban geographer is the increasing specialization and abstraction of knowledge. The course leader explains the principles which underlie this progression, "In first year we do cases to demonstrate theory, in second year we do theory to demonstrate cases, in third year...students are involved in the production of knowledge...some form of research to think about theory and case and the relationship between the two". She explains how in the course students are introduced to "different ways of knowing the city". She elaborates, "You can know the city through primary research...you can know the city on a much more conceptual level...you can know it on a much more abstracted level...(for example) through Marx's theories of the city”. Thus the logic of the curriculum is the interplay of theory and case with increasing levels of abstraction with one of the central aims of apprenticing students to the epistemological move from the particular to the general - reminiscent of Bernstein's vertical forms of knowledge ${ }^{2}$.

\footnotetext{
${ }^{2}$ Bernstein distinguishes between two types of vertical knowledge, hierarchical knowledge structures and horizontal knowledge structure (Bernstein 1999). Further exploration of Human Geography as a discipline - with its interesting hybridity of physical and social science - is necessary to determine which knowledge structure is most apt.

E-mail:sshay@ched.uct.ac.za
} 
Students experience first hand the challenges of this interplay of theory and case through the field research projects as they juxtapose what is presented to them in the classroom with the lived experience of the 'researched'. In the year of the study, the 'researched' were members of a Coloured township situated on the northern outskirts of Cape Town where the project convener had been involved for several years with a community-based research group on an anti-eviction campaign. The UG300 students, with the assistance of the community members, surveyed the informal settlement dwellers. The survey data enabled the community to produce a map of backyard living, along with tables of information about the backyard dwellers.

The field research project requires students to produce a written group report. They must also give an oral presentation of their research findings to the rest of the class as well as invited members of the community. In addition they are required to keep a reflective journal of the research process. Both the written and oral reports are marked and students are given extensive feedback. The written report counts for $40 \%$ of their overall course mark and is moderated by an external examiner. The project convener's aim is that through this primary research students are "going out and producing the knowledge (and) thinking critically about how information gets produced, urban theory, urban knowledge and assumptions about, e.g. backyard squatting”. She notes, "My agenda is to get them excited about research because if you want to continue in Human Geography then it is a research type of orientation course”.

When asked what she is looking for in assessing these projects, the project convener notes, "What I want them to do with the report is to think about how do you use field research to make an argument...”. In both the presentations, oral and written, she focuses on students' assertions. In the feedback she continually asks of her students, "How do you know what you know?”. In the interview, she gives an example of a student the previous year that had claimed in her presentation that some women were lazy because they were simply living off their mothers. The convener said, "I was quite harsh with her...I said 'How do you know that? What is your evidence for that? Where did you get E-mail: sshay@ched.uct.ac.za 
that information?' '”. She is also looking for evidence that students could rise above the case. "A really good report is not saying 'this is the case' but saying 'this is what I can draw from it; this is how I can step up out of the detail particularities'. That is what I'm looking for....”. Thus what is being formally and explicitly assessed is the students’ attempts at what Bernstein would call 'vertical discourse' or the production of verticality.

The logic of valuing this kind of knowledge production as opposed to another is a product of the course's location within a university, a science department, a discipline that values a particular kind of research and envisions itself producing particular kinds of knowledge workers. Aligned with this is the course leader herself and her own firm location within academe. In interview I explored the possibility of different interpretive frames. "What if someone else was to assess these projects, for example, the community members who attend the oral presentations?” I asked. The project convener speculates, “They would probably value different things, for example, the usefulness of the report”. In contrast she states, "My criteria for the report are definitely not anything to do with usefulness...even if the student is excellent, the reports will be not be very useful.”

Thus in terms of the assessable 'outcomes' what the course unambiguously values is the ability of students to make valid, well-substantiated assertions, to move from the particular of case to the generalities of theory. As a member of the academic community the convener knows how to assess this kind of epistemological move. She is clear that what is not being assessed is the usefulness or the meaningfulness of this knowledge to other kinds of users, those outside academe. "This is an academic project”, she argues.

Interestingly, however, the convener requires her students to include as appendices some products which are intended to go back to the community, for example, a table of raw data and two life history interviews. These are not formally assessed (except as a requirement of the report), they are not commented on by the community members, and as of yet, they have not actually been turned over to the community members. On reflection she argues that while these products are materially of limited usefulness, they serve as proxies for less tangible social 'outcomes' (or forms of knowledge?) which the E-mail: sshay@ched.uct.ac.za 
research project has enabled -- the experience of working together (albeit temporarily) across race and class divides, the ability to engage with others outside one's comfort zone, and the opportunity to develop friendships. She writes, “These are important steps, and important 'products' in themselves that grow from partnerships and form the processes of engagement in community-based field projects” (Oldfield 2005).

These 'outcomes' appear not to be assessable in any direct way and yet they are evidence of rich learning for her students, herself and the community members. Thus we observe the limits of assessment. Constrained by the field which values the 'stepping out of the particular' - we have established repertoires for assessing (and giving marks to) the products and processes of the vertical knowledge. We can also by proxy assess a number of intangible social processes but here we enter the realm of uncertainty. Assessment as practiced in higher education has reached its limit.

I now turn to RDS400 where, like UG300, students must learn to 'step out of the particular'. In contrast, however, the RDS curriculum, given its field and institutional position, explicitly values different kinds of knowledge which introduces interesting assessment challenges.

\section{RDS400 field research project}

Located in the same department but at the postgraduate level, RDS400 is the introductory course of the Honours programme in Risk Disaster Science. The RDS programme was recently established in response to widespread socio-economic and environmental threats which have significantly increased disaster risk locally, continentally, and globally. The programme convener is the director of a disaster mitigation unit, housed in the EGS department, and the research project convener is one of the principle researchers for the unit. This unit provides services for government and non-government organizations in the form of research and training. Thus the staff straddles two worlds -- one foot firmly planted in the field of development and one somewhat less firmly planted in academe. E-mail: sshay@ched.uct.ac.za 
Despite this precarious status, the university location offers the unit an opportunity which they have seized enthusiastically -- to develop professionals in the emerging field of Risk Disaster Science.

The programme's disciplinary location is at the nexus of the department's three disciplinary strands - environmental management, physical geography and human geography. The teaching staff comes from different disciplines, some from the social sciences, others from the physical sciences. What holds them together is an ideological commitment to "science in the service of society", a commitment to produce graduates who "can make a difference” in the face of an increasing global vulnerability to risk disaster. The programme convener argues, "If your primary philosophy or ideology is to see improvements, to see upliftment, to see progressive developmental change in society, then essentially you look for vehicles that will allow that to happen.” For her the vehicle is the emerging field of Risk Disaster. She reflects, "The question I ask is, 'What is the university's role in helping to ameliorate or avert or manage those problems?' and this (programme) is one small contribution that the university can make ...you're building a mass of people who maybe (can) make a difference to the broader community.”

However, producing graduates who can "make a difference” requires some important shifts in what is traditionally valued in a science curriculum. The programme convener notes that for students from a biophysical undergraduate experience to use their "science in the service of humanity requires a different head space... a different set of skills, set of attitudes”. Some of the necessary shifts in both curriculum and pedagogy include: from a knowledge-driven curriculum to the application of knowledge to real problems, from disciplinary to multi-disciplinary perspectives, from individual to group products, from classroom-based learning to learning in unfamiliar, unstructured environments. The project convener argues, "The real world is highly complex and often it is easy to oversimplify things. I think that (the programme) presents the opportunity for students to develop insight, which is not just based on learning texts, but to think and engage with the world critically...Universities are based on theoretical conceptual frameworks. What we are essentially doing is testing that out or learning how to apply that and that is where E-mail: sshay@ched.uct.ac.za 
one has to learn how to think.” In addition to these shifts, the programme convener argues for what she calls 'softer elements' which professionals in this field require, for example, accountability, communication, initiative, and conflict management. She concludes, "If we are going to make a difference in at risk communities we actually have to harness science and we have to harness wisdom”.

The field research report center around a risk assessment conducted in a nearby African informal settlement where the staff has developed partnerships with local community organizations. In the year of the study the research focus was fire risks, for example, one group assessed the fire risks for children in this particular settlement. Over a period of several weeks, the students, working in groups, collected data through various means. In the case of the project focused on children, the students interviewed adult heads of households and conducted activities with school children at the local primary school.

The formal assessment requirements for RDS400 course are similar to those of UG300: the students are required to produce a joint written report and oral presentation, as well keep a journal of their field assessment experience. Consistent with the Urban Geography project convener, the RDS staff is also clear on the aim of training researchers. The project convener notes "I cannot claim that they (are doing) development work because nothing might change from their presence there. Researchers is primarily what they are”. However she adds, "It is not just about the students doing research...it is about relationships that are established...exchanges between students, local institutions and the community”. She argues that the exchange of knowledge and information, in this case about the reduction of fire risks, creates a "learning environment” among the various key roleplayers.

In interviews with the staff the formal assessment of the written reports raises two sets of challenges. The first is the tension between what I argue are different kinds of knowledge. The programme convener refers to it as the tension between different kinds of 'outcomes' which the course is trying to meet, the educational vs. the developmental or the academic vs. the professional. She argues, “There's a tension between delivering E-mail: sshay@ched.uct.ac.za 
good academic outcomes against providing outcomes that inform society. It's slightly different...we must balance the academic requirements of the Science Faculty against the professional requirements of the field.”

An example of this tension are the multiple audiences for the written reports. On one hand, the students are writing (and therefore must learn to write) for an external audience, for example, the local community needing information about fire hazards. The convener notes, "There reports have to be pretty user-oriented which is a challenge for students to move outside of classic academic discourse”. On the other hand, there is the academic audience, for example, the internal and external examiners. The programme convener described an assessment task where students had to synthesize across physical and human geography in response to a particular environmental risk problem. The convener reported the response of the external examiner, “ 'Where’s the theory? Do they do any reading for this course?' ". These different audiences privilege not only different products, but different kinds of knowledge resulting in a tension for the teaching staff.

The second set of challenges for the RDS staff is the establishment of interpretive frameworks for assessing these complex performances. For the programme convener it is a failure on the part of the staff to be "explicit”. She repeatedly raises the difficulties of making explicit these valued professional competencies. In the first year of the course, she notes, "We gave students a lot of content around hazards and risks and vulnerabilities, but around say, responsible community practice...I don’t think we addressed it completely...it wasn't so explicit”. When it came time to assess the projects, she argued that they could not mark students against new "game rules”. The staff also questioned whether some of these 'softer skills' could be taught. In the first year one group project went badly largely due to one particular student, “He just didn’t want to be part of a group”. On further reflection she notes, “I don’t know whether you can actually train somebody to think in terms of the group.”

\section{Discussion}

E-mail: sshay@ched.uct.ac.za 
I now return to the question which this paper set out to explore: In the context of these service learning courses, what is assessed and what is not assessed, and why? An exploration of the assessment of the field research reports in both of these courses reveals that what is clearly valued is knowledge production; in both courses students are apprentice knowledge producers. What is assessed in both sites is the process of knowledge production and the meaningfulness of the knowledge in relation to more or less explicit criteria. Academics through their own socialization processes know how to assess the research processes and products of the discipline. In both courses the introduction of a research journal was an important innovation for reflecting on the research process, both for the students and the staff. There are epistemological and methodological ground rules which define this knowledge production practice, for example, what constitutes sound evidence, valid and respectful assertions, and a defensible argument. Both courses illustrate how through a rich combination of assessment opportunities -- the oral presentation, the written presentation and the journal - students are given the opportunity to develop and showcase a range of skills required of field researchers in urban geography and risk disaster management. Thus the methods of assessment, the criteria, the feedback all support (more or less) the acquisition of theoretical knowledge. In other words, the assessment practices are consistent with the logic of the regulative discourse of the field in which it is located.

But in their commitment to boundary-work, these service learning courses inevitably challenge this regulative discourse. They are interested in additional forms of knowledge which prove more challenging to assess. These forms of knowledge are articulated in different ways by the staff in the two courses. For the UG300 convener they are expressed as social knowledges with strong affective dimensions. For the RDS staff they are articulated as forms of professional knowledge. While Bernstein's categories of horizontal and vertical may be useful for describing differences between disciplinary forms of knowledge (e.g. the difference between sociology and economics), as noted earlier their application to the knowledge boundary work of service learning appears limited. What seems to be missing in Bernstein's discourses is a form of knowledge which has elements of both the vertical and the horizontal, which emerges from the E-mail: sshay@ched.uct.ac.za 
particular, takes on a theoretical form, but derives its meaning in the re-application to the particular.

Whether these forms of knowledge valued in service learning are hybrids or something altogether different to Bernstein's categories, what emerges from the cases is the limitations of traditional forms of assessment. These forms of knowledge are embedded in and thus dependent on practice for their realization. Students cannot learn ‘accountable community practice’ or ‘conciliatory conflict management' in a classroom. These are “operational knowledges” (Bernstein 1999) which can only be activated in contexts. It is the development of a social and/or professional 'gaze' which can only be transmitted tacitly through modeling, activated in experience and practice. This gaze enables the student to "recognize, regard, realize and evaluate legitimately the phenomena of concern” (Bernstein 1999, p. 170).

The limitations of academic assessment to value other than vertical forms of knowledge creates different degrees of tension between the two courses. It could be argued that there is a relatively strong alignment between the UG300 course aims and what is actually valued in its assessment. In contrast the RDS400 course sets up interesting misalignments given its 'straddling position' between the field of academe and the field of development. When boundaries are weakened - between subject contents, between the discipline and the field of practice, between theoretical knowledge and different kinds of knowledge there is a challenge to the existing regulative discourse, to the alignment between what universities value and what is assessed. When service learning curricula value certain things which can be more or less successfully taught but not assessed they create fascinating and uncomfortable misalignments.

\section{Conclusion}

These assessment challenges are not unique to service learning curricula. They are relevant to any curricula which work at the boundaries, for example, professional programmes of law, medicine, engineering and teaching. Even in these programmes with E-mail: sshay@ched.uct.ac.za 
long traditions of valuing different kinds of knowledge, the challenges of assessing context-dependent complex performances have not been given sufficient theoretical attention. Responses to these challenges have been largely technical emphasizing the development of more reliable assessment technologies, for example, alternative methods of assessment, more explicit rubrics, more rigorous moderation. While these technologies at some point deserve attention, they cannot be the starting point. The starting point is an interrogation of the values which constitute the basis of academics' judgments of student performance - in Bourdieu's (1996) terms, the underlying principles of vision and division. A critique of these interpretive frameworks is likely to result in two positions: some may wish to argue that the boundaries demarcating academic knowledge are real and necessary. The university, they will argue, is conservative; its role is to converse its particular forms of capital. Others, including our service learning colleagues, would argue that given the changing role of the university in society, shifting frames of reference are essential.

It is not the aim of this paper to commit to either of these positions, but rather to briefly consider the implications for assessment. The conserving position - the one which seeks to protect the boundaries which demarcate academic knowledge - will acknowledge the limits of assessment in relation to complex performances. From this position, academic programmes will resist the pressure to make claims for skills and forms of knowledge which it cannot deliver. Having acknowledged these limits effort can be invested in professionalizing the means by which we socialize students into the academic habitus. The transforming position - the one which argues for the need to shift interpretive frameworks - has a much more difficult task of re-imaging the university. This task is central to the heart of service learning in South Africa. If this latter position is to gain any significant ground, however, it will need, among other things, a more elaborated language for talking about knowledge and its multiple forms and contexts of realization. Shifts in interpretive frameworks will only occur if the membership of the interpretive community is reconstituted and the 'rules of the game' are rewritten so that theoretical knowledge does not trump all. This will inevitably cause disruptions to the existing social order, disruptions which members of the conservation camp might argue will only serve to E-mail: sshay@ched.uct.ac.za 
undermine academic knowledge production. My argument is that either of these positions is supportable in principle. What is not supportable is the failure on the part of the academic interpretive community to recognize the value-based nature of existing assessment judgments and practices. Service learning has at least taught us this much.

\section{Acknowledgment}

I wish to thank the colleagues on the JET Service Learning research and development project for their input into this paper through a variety of formal and informal ways. In particular, I wish to thank Dr. Linda Cooper and Prof. Tim Stanton from the project and Dr. Rob Moore who read and commented on an earlier draft.

E-mail: sshay@ched.uct.ac.za 


\section{References}

Barnett, R. \& Coate, K. (2005) Engaging the Curriculum in Higher Education (Society for Research into Higher Education \& Open University Press).

Bernstein, B. (1975) Class, Codes and Control (London, Routledge \& Kegan Paul).

Bernstein, B. (1999) Vertical and Horizontal Discourse: An essay, British Journal of Sociology of Education, 20(2), 157-173.

Bernstein, B. (2000). Pedagogy, Symbolic Control and Identity. Revised Edition. (Lanham: Rowman \& Littlefiled Publishers, Inc.).

Biggs, J. (1996) Enhancing teaching through constructive alignment, Higher Education, 32, 347-364.

Bourdieu, B. (1996) The state nobility: Elite schools in the field of power (Cambridge, Polity Press).

Bourdieu, P., \& Wacquant, L. (1992) An invitation to reflexive sociology (Cambridge, Polity Press).

Breier, M. (2004) Horizontal discourse in law and labour law, in J. Muller, B. Davies, \& A. Morais (eds) Reading Bernstein (London, Routledge/Falmer), 222-235.

Broadfoot, P., \& Pollard, A. (2000) The changing discourse of assessment policy: The case of English primary education, in Filer, A. (ed.) Assessment: Social practice and social product (London, Routledge/Falmer), 11-26.

Ensor, P. (2002) Curriculum, in: Cloete, N., Fehnel, R., Maassen, P., Moja, T., Perold, H., Gibbon, T. (eds) Transformation in Higher Education: Global Pressures and Local Realities in South Africa (Centre for Higher Education Transformation).

Government Gazette No. 18207 (1997) Education White Paper 3: A programme for transformation of higher Education (Pretoria, South Africa).

Knight, P. (2005) Assessing complex achievements, in: McNay, I. (ed) Beyond mass HE: Building on experience (Society for Research into Higher Education \& Open University Press).

Knight, P. (in press) The local practices of assessment. Assessment and Evaluation in Higher Education.

Knight, P. \& Yorke, M. (2003) Assessment, Learning and Employability (Society for Research into Higher Education \& Open University Press).

McMillan, J. (2002). The Sacred and Profane: Theorising Knowledge Reproduction Processes in a ServiceLearning Curriculum. In S. Billig \& A. Furco (eds), Service-Learning Through a Multidisciplinary Lens (Greenwich, Connecticut: Information Age Publishing).

Moll, I. (2004) Curriculum responsiveness: The anatomy of a concept, in H. Griesel (Ed) Curriculum responsiveness: Case studies in higher education (South African Universities Vice-Chancellors Association), 1-20.

Moore, R. (2000) The (re)organization of knowledge and assessment for a learning society: The constrainsts on interdisciplinarity, Studies in Continuing Education, 22(2), 183-199.

Moore, R. (2004) Responding to market and society: Curriculum challenges in a business school. In: H. Griesel (Ed) Curriculum responsiveness: Case studies in higher education (South African Universities Vice-Chancellors Association), 217-236.

E-mail: sshay@ched.uct.ac.za 
Moore, R. \& Lewis, K. (2004) Curriculum Responsiveness: The Implications for Curriculum Management. In: H. Griesel (Ed) Curriculum responsiveness: Case studies in higher education (South African Universities Vice-Chancellors Association), 39-56.

Muller, J. (2000) Reclaiming Knowledge (London, Routledge/Falmer).

National Commission on Higher Education (NCHE) (1996). A Framework for Transformation. Pretoria: Department of Education.

Oldfield, S. (2005) Who’s serving whom? Partners, process, and products in service learning projects. Unpublished paper presented at Service Learning Symposium, September, 2005.

Shay, S. (2004) The assessment of complex performances: A socially-situated interpretive act, Harvard Educational Review, 74(3), 307-329.

Shay, S. (2005) The assessment of complex tasks: A double reading, Studies in Higher Education, 30(6), 663-679.

South African University Vice Chancellor Association (SAUVCA) (1999). Facilitatory Handbook on the Interim Registration of Whole University Qualifications by June 2000. (Pretoria: SAUVCA).

Young, M. (1998) The Curriculum of the Future, (London: Falmer Press).

Young, M. (2003) Curriculum Studies and the Problem of Knowledge: Updating the Enlightenment?, Policy Futures in Education, 1(3), 553-564.

E-mail: sshay@ched.uct.ac.za 